\title{
Reputable Internet Retailers' Service Quality and Social Media Use
}

\author{
Yun Kyung Cho \\ Metropolitan State University of Denver \\ ycho5@msudenver.edu \\ Cynthia L. Sutton \\ Metropolitan State University of Denver \\ suttoncy@msudenver.edu
}

\begin{abstract}
Previous literature suggests that retailer reputation is a key competitive factor because customers trust reputable retailers. According to the conventional reputation creation framework, service quality plays a critical role in reputation building. A retailer's reputation is enhanced when customers perceive high service quality. Our research question addresses whether an Internet retailer's service quality is associated with the retailer's reputation in reality beyond customer perception. To answer the question, this study uses an objective, not perceptual, measure of reputation and compares service quality of reputable and non-reputable Internet retailers. Internet retailers use social media marketing to build their reputation. Therefore, this study also examines the relationship between social media use and reputation. Service quality information of 619 Internet retailers was collected and analyzed from online customer reviews. Retailer use of social media was measured by visiting their websites. The binary logistic regression models show some unmatched linkages between service quality and reputation. Our results suggest that reputable retailers do not provide higher service quality which disproves the conventional reputation creation framework. Instead, this study suggests social media marketing is an alternative source of reputation.
\end{abstract}

Keywords: Reputation; Internet retailing; E-service quality; Order procurement quality; Order fulfilment quality 


\section{INTRODUCTION}

Since amazon.com opened their online retail solution in 1995, Internet retailing has become an important industry sector. In the new millennium, web-based information technology (IT) became more affordable and a vast number of retailers have launched this convenient online business solution and actively participated in Internet retailing. Today, every firm or individual can develop an online store and compete in virtual space. Inevitably, intense competition became the norm. This shows a different picture of the industry sector from the one when the Internet was not available and a few retailers that had a strong physical presence dominated in the market.

In today's intense competition, Internet retailers' service quality plays a critical role in identifying reliable retailers. A vast amount of research on e-service quality has validated that e-service quality influences customer satisfaction and loyalty [1-4]. The connection between service quality and customer loyalty is not new in the Internet era. The connection previously had been proven important for brick-and-mortar retailing [5], [26]. However, it is more important now since the Internet significantly enhances information symmetry between sellers and buyers [6-8]. Online customer reviews including social media greatly contribute to information symmetry. Customers can post comments about their shopping experience through online social platforms such as Facebook, Twitter, or YouTube. That information is shared with a vast number of social media users which potentially influences the behavior of other online shoppers [9-13]. In this Internet era, information indicating retailer service quality has become more critical because online shoppers use this information to select retailers [1-2].

Another factor that influences shopper behavior is retailer reputation; online shoppers perceive reputable retailers to be trustworthy [14-18]. Trusting reputable retailers is understandable when we look at the conventional reputation creation framework. The framework proposes that customer perception of high service quality positively influences the perceived reputation of the retailer [19-20]. Based on the framework, we can attribute reputable retailers to be high quality service providers. The customers' reputation seeking behavior can be explained by the connection between service quality and reputation.

However, the connection appears to be limited to customer perception. Online customers who experience an Internet retailer's high service quality perceive the retailer's reputation as high [16], [20]. In 
other words, the connection between service quality and retailer reputation may only reside in the reputation creation phase within customer perception. The connection beyond reputation creation needs to be objectively studied where customer perception of service quality and reputation are separate.

The purpose of this study is to objectively examine the connection between service quality and reputation. This can be done by comparing service quality of reputable and non-reputable Internet retailers and by measuring reputation objectively. In this way, customers who assess service quality do not also evaluate reputation. Using the objective reputation measure, this study will test if reputable Internet retailers deliver high quality services as the conventional reputation creation framework suggests.

An alternative source of reputation is social media. Many Internet retailers invest in social media marketing to establish brand reputation [9-13]. This study will empirically show whether social media use by Internet retailers and their service quality are associated with the retailers' reputation.

This study contributes to our understanding of Internet retailers' reputation in several ways. A deductive approach to the conventional framework provides a complementary and comprehensive view of reputation creation and maintenance. The conventional framework proposes that high service quality positively influences a retailer's reputation within customer perception. However, the true relationship between service quality and reputation beyond customer perception has not been established. As a result, we do not know exactly if reputable retailers are really higher service quality providers than non-reputable retailers. Thus, there is a need to advance our understanding of reputation.

Furthermore, the large sample size of this study will provide valuable insights into the connection between reputation and service quality. The more than 600 retailers in the sample were selected based on customer reviews about their service quality. On average, 1,252 customers evaluated each retailer's service quality in our sample. Finally, this study covers both online and offline service quality for each retailer. Internet retailing encompasses not only order procurement using an Internet retailer's online tool - mostly its website - but also offline order fulfillment for on-time order delivery to the customer. Service quality in both heterogeneous retail operations is examined. Overall, this study rigorously examines the relationship between service quality and reputation both in theory and methodology. 


\section{LITERATURE REVIEW AND THEORETICAL DEVELOPMENT}

Argenti and Druckenmiller [21] define reputation as "the collective representation of multiple constituencies' images of a company built up over time and based on a company's identity programs, its performance and how constituencies have perceived its behavior." Thus, reputation is a public judgement of a company's collective image that has been shaped over time. This special kind of public judgement often unduly influences customer perceptions because people tend to exalt high reputable companies. An organization's reputation is critical to success because it increases customer loyalty [20], [25]. Compared to non-reputable retailers, customers tend to elevate the service quality of reputable retailers [14], [17], [23] and return fewer products with the same defects [24].

Studies on Internet retailer reputation are divided into two groups. The first group focused on the reputation creation process asserting that reputation was the outcome of customer relations [15]. Online customers form the retailer's reputation based on their experience with the retailer's online web design/functionality and offline order fulfillment factors [19-20]. The reputation shaping process also was influenced by small service cues, such as return policy, privacy policy, and retailer introduction on the homepage [18]. Findings in this first group suggest that service quality is strongly associated with retailer reputation.

The second group of studies emphasized the outcomes of reputation and why reputation creation is important for Internet retail businesses. Reputation is a key intangible asset that provides a competitive advantage [18] and main outcome of reputation is customer loyalty [16-17], [25]. Regarding producing customer loyalty, the role of reputation appears to be overlapped with service quality. In the last two decades, e-service researchers have reported a sequential relationships from service quality to customer satisfaction and, then, to customer loyalty [1-4].

However, the mechanisms of producing customer loyalty appear different between service quality and reputation. As noted above, customer satisfaction is the mediator between service quality and customer loyalty. In the relationship between reputation and customer loyalty, trust serves as a mediator. Ruimei et al. [16] reported that perceived reputation is positively associated with trust. Jin, Park, and Kim [17] found a relationship between trust and customer satisfaction. In their study, reputation positively influences trust, trust influences satisfaction, 
and satisfaction influences loyalty. Those studies verify that reputable retailers win customer loyalty through trust. Their findings are reasonable because online customers need to trust the retailer before transactions because they provide their personal and financial information as part of a transaction [18]. They want to reduce perceived risk from online transactions, and one indicator for trust that they can rely on is the retailers' reputation [22].

A noticeable similarity in the two groups of studies is the use of a perceptual reputation measure. This is largely because they investigate the psychological structure of reputation creation or the behavioral outcome of reputation on the customer side. As a result, those studies were useful in predicting customer reaction to Internet retailers with different levels of service quality or reputation. Nevertheless, they do not explain how Internet retailers with and without reputation perform differently regarding service quality. The connection between high service quality and high reputation in customer psychology increases the probability that reputable retailers are high quality service providers [19-20]. However, this connection should be validated against empirical data.

If reputable Internet retailers provide higher quality services than non-reputable retailers, we can confirm that the reputation creating process proposed by previous studies is working in reality. If this study validates the connection, findings in this study combined with the findings of the first group in the previous studies can provide stronger evidence of the connection between service quality and reputation. This reciprocal approach between induction and deduction is especially valuable given that there is an alternative reputation creation path through customer relationship management. In particular, many Internet retailers use social media marketing [9-10], [12-13] and its impact on reputation should not be neglected. Thus, service quality may be required for reputation creation. However, reputable retailers may not be high quality service providers because they can gain reputation from alternative sources such as social media marketing. Figure 1 illustrates theoretical backgrounds of the focal relationships in this study. Table 1 and Table 2 summarize previous studies that are relevant to the focal relationships.

To examine the connection between service quality and reputation, service quality should be properly defined and measured. Service quality has been defined as the gap between perceived performance and expectation [26]. Nevertheless, defining service quality in Internet retailing is complicated by various factors involved in Internet retailing [27]. To study service quality in Internet retailing, the goals and processes of two heterogeneous retail operations - online procurement and offline 
order fulfillment - should be clearly defined. The goal of online procurement is to guide customers to the online transaction so that the retailer wins an order. Because an online transaction occurs mostly in the retailer's website, the website's cosmetics and functionality are important requirements for the order procurement [3], [27].

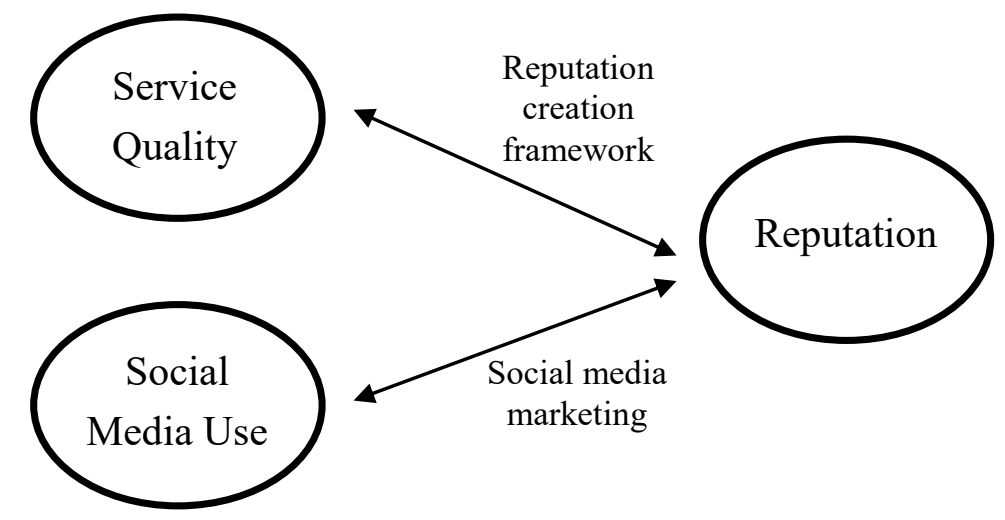

Figure 1. Focal relationships and their theoretical backgrounds

Quality of website design covers the cosmetic side where content arrangement, font, color, and other design factors collectively appeal to web-users, and induce a behavioral intention to use the website for online transactions. Web functionality also is influenced by multiple factors. A retail website should deliver correct information about merchandise and services. Many customer complaints or product returns resulted from poor clarity of online information [28]. Another important factor in functionality is a retail website's search efficiency [29-30]. One major reason that people use online shopping is convenience. As such, online customers want to find information easily from a retailer website. An Internet retailer's high order procurement quality means their online order procurement process satisfies customers with those cosmetic and functionality factors.

In contrast to order procurement, the goal of order fulfillment is timely delivery of an ordered item to the customer. Order fulfillment entails actual delivery of the item through pre-organized supply chains. This offline process is completely separate from online procurement and high order procurement quality cannot guarantee high order fulfillment quality. One major order fulfillment quality factor is on-time delivery [4], [31-33]. After placing an order online, customers want to receive the order in a timely manner. Delayed delivery increases their anxiety which leads to dissatisfaction. One way to lessen the anxiety is an order tracking 
service which is another service factor in the order fulfillment process [30]. More fundamentally, on-time delivery requires product availability. Retailers showcase their product using their websites. If certain merchandise on the website is not available when customers order the product, delivery delay is inevitable. In this regard, availability of product is an important factor related to order fulfillment quality.

Table 1. Literature on the relationship between service quality and reputation in Internet retailing

\begin{tabular}{|c|c|c|}
\hline Author(s) & Year & Major finding(s) \\
\hline Punyatoya [14] & 2019 & $\begin{array}{l}\text { Online service quality and retailers' perceived } \\
\text { reputation independently influence trust. }\end{array}$ \\
\hline Terblanche [15] & 2009 & $\begin{array}{l}\text { Customer experience with a retailer leads to } \\
\text { customer evaluation of reputation (conceptual } \\
\text { paper). }\end{array}$ \\
\hline $\begin{array}{l}\text { Ruimei et al. } \\
{[16]}\end{array}$ & 2012 & $\begin{array}{l}\text { Perceived security of using an online store } \\
\text { increases perceived reputation of the retailer } \\
\text { and this increases trust. }\end{array}$ \\
\hline $\begin{array}{l}\text { Jin, Park, and } \\
\text { Kim [17] }\end{array}$ & 2008 & $\begin{array}{l}\text { Perceived retailer reputation increases trust and } \\
\text { customer satisfaction. }\end{array}$ \\
\hline $\begin{array}{l}\text { Wang, Beatty, } \\
\text { and Foxx [18] }\end{array}$ & 2004 & $\begin{array}{l}\text { A retailer's perceived reputation and service } \\
\text { quality such as web security and return policy } \\
\text { increases trust. }\end{array}$ \\
\hline $\begin{array}{l}\text { Järvinen \& } \\
\text { Suomi [19] }\end{array}$ & 2011 & $\begin{array}{l}\text { Service quality is one of the reputation } \\
\text { predictors (conceptual paper). }\end{array}$ \\
\hline $\begin{array}{l}\text { Caruana \& } \\
\text { Ewing [20] }\end{array}$ & 2010 & $\begin{array}{l}\text { A retailer's service quality increases perceived } \\
\text { reputation and this increases customer loyalty. }\end{array}$ \\
\hline $\begin{array}{l}\text { Kim \& Lennon } \\
{[22]}\end{array}$ & 2013 & $\begin{array}{l}\text { A retailer's perceived reputation and service } \\
\text { quality independently affects customer emotion } \\
\text { and perceived risk of using the retailer and their } \\
\text { repurchase intention. }\end{array}$ \\
\hline Walsh et al. [23] & 2016 & $\begin{array}{l}\text { Perceived reputation of a retailer affects } \\
\text { customer product return. The higher the } \\
\text { reputation, the lower the return. }\end{array}$ \\
\hline Har \& Eze [25] & 2011 & $\begin{array}{l}\text { Perceived reputation increases repurchase } \\
\text { intention. }\end{array}$ \\
\hline
\end{tabular}

Previous studies found that service quality positively influences reputation in the reputation creation process within customer perception 
[19-20]. The connection can be validated deductively by examining reputable retailers' service quality beyond customer perception. This study hypothesizes the following relationship beyond customer perception:

H1: An Internet retailer that delivers high service quality, both in order procurement and order fulfillment, is highly likely to be a reputable retailer.

Service quality is not the only factor that influences reputation. Today's firms implement customer relationship practices more than in the past. The purpose of customer relationship management is to gain customer attention and increase brand and/or firm reputation. Among many customer relationship practices, Internet retailers are quite active in social media marketing. Using dedicated online community platforms such as Facebook, Twitter, YouTube, and others, they seek to approach online customers, study and address their needs and preferences, bond with them, and more effectively market their products and services. It is believed that reputation creation resulting from providing quality services and using social media marketing should be complementary so that the positive effect on reputation can be maximized. Otherwise, poor service quality or negative word-of-mouth in social media can ruin a retailer's reputation [7-8]. Riquelme et al. [24] demonstrate that information about a retailer's unfair price will spread quickly online, dramatically decreasing the retailer's reputation and inducing customer retaliation online. Thus, reputation is very volatile in the online context. It is difficult to build but easy to destroy. Regardless of using service quality management for reputation creation, Internet retailers should be aware of social media's influence on reputation.

Recent studies provide strong evidence that social media marketing influences brand reputation. Using social media, Internet retailers can promote their brand value and allow customers to share positive word-of-mouth efficiently, leading to reputation building [34]. According to Kim and Ko [13], social media marketing includes various activities such as sharing and updating information, providing customized services, making customers participate in information sharing all of which entice customers to bond to the brand. Through these activities, brand awareness among online customers increases and brand loyalty, which is the precursor of reputation, is created [9-10], [35-38].

Social media revolutionized information sharing which is essential for judgement of reputation. Social cognitive theory assumes that individuals have limited capacity to process information which makes 
reputation judgement difficult and inaccurate [39]. However, social media push that limit. Advances in communication and information sharing by social media has been explained by multiple existing theories. One of them is social presence theory. This theory emphasizes social presence, which refers to the state of being connected with the other party in the communication, as a key component in communication quality [40-41]. Social media maintain and update information on a real time basis, which offer continuous social presence to online users for quality communication [42].

Medium richness theory explains the novel capacity of social media as an information system. This theory asserts that information richness in a medium reduces information equivocality. Different formats of information (e.g., video, script, and picture) that social media can transmit either person-to-person or person-to-public make information about a focal topic rich and minimize the amount of equivocality [43-44]. If online users find accurate information about Internet retailers on a real time basis via social media, social media marketing positively influences online customers' judgment of reputation.

Etter, Ravasi, and Colleoni [45] differentiate between traditional media and social media regarding the mechanism in which they affect firm reputation. Traditional media depend upon vertical top-down dissemination of information called "broadcasting" while social media use horizontal networked dissemination by information "coproduction". Consequently, information in traditional media is highly homogeneous among different media outlets after the information is processed through similar professional norms and procedural isomorphism. In the case of social media, information is heterogeneous from a multitude of disseminators in public platforms where information contexts for the same kind of information are different. The efficient process of information added to the popularity of social media makes social media marketing a key tool for reputation building [9-10], [13].

Previous findings demonstrate the positive connection between social media marketing and brand loyalty within customer perception [34], [37]. The connection should be validated deductively beyond customer perception by objectively measuring reputation. This study investigates the relationship between Internet retailer use of social media and reputation.

$\mathrm{H} 2$ : An Internet retailer that uses social media (i.e., Facebook, Twitter, and YouTube) is highly likely to be a reputable retailer. 
Table 2. Literature on the relationship between social media use and brand reputation

\begin{tabular}{|c|c|c|}
\hline Author(s) & Year & Major finding(s) \\
\hline $\begin{array}{l}\text { Weiger, Wetzel, and } \\
\text { Hammerschmidt [9] }\end{array}$ & 2017 & $\begin{array}{l}\text { Engagement among online community } \\
\text { members (Facebook) influences brand } \\
\text { equity. }\end{array}$ \\
\hline $\begin{array}{l}\text { Jakic, Wagner, and } \\
\text { Meyer [10] }\end{array}$ & 2017 & $\begin{array}{l}\text { Interaction among online community } \\
\text { members (Facebook) influences brand } \\
\text { trust. }\end{array}$ \\
\hline $\begin{array}{l}\text { Jung, Kim, and Kim } \\
\text { [12] }\end{array}$ & 2014 & $\begin{array}{l}\text { Perceived benefits of using online brand } \\
\text { communities influence community } \\
\text { members' brand trust. }\end{array}$ \\
\hline Kim \& Ko [13] & 2012 & $\begin{array}{l}\text { Social media marketing activities (such as } \\
\text { social media's entertainment, interaction } \\
\text { and creation and delivery of word of } \\
\text { mouth) increases brand equity. This } \\
\text { influences customer repurchase intention. }\end{array}$ \\
\hline $\begin{array}{l}\text { Dijkmans, Kerkhof, } \\
\text { and Beukeboom [34] }\end{array}$ & 2015 & $\begin{array}{l}\text { Intensity of social media use by customers } \\
\text { is positively related to their engagement in } \\
\text { social media activities and this increases } \\
\text { customer perception of reputation in an } \\
\text { airline company. }\end{array}$ \\
\hline $\begin{array}{l}\text { Helal, Ozuem, and } \\
\text { Lancaster [37] }\end{array}$ & 2018 & $\begin{array}{l}\text { Use of social media marketing in fashion } \\
\text { apparel and accessories industries } \\
\text { increases brand perceptions among } \\
\text { customers. (Case study) }\end{array}$ \\
\hline Mathur [38] & 2018 & $\begin{array}{l}\text { Customer engagement on social media } \\
\text { increases brand equity through customer } \\
\text { participation in social media response and } \\
\text { their brand recommendation. }\end{array}$ \\
\hline
\end{tabular}

\section{METHODOLOGY}

To test the hypotheses, this study sampled Internet retailer performance of order procurement services and order fulfillment services. We found that dedicated online customer review sites offered Internet retailer service quality information from online customer experience with them. The problem was that many of them did not carry online customer reviews on both retailer order procurement and order fulfillment practices with clear measurement items. Nevertheless, one retailer review site (BizRate.com) sent systematic surveys to customers who had transactions 
with its affiliated retailers and reported the survey results on its website. The survey asked online shoppers about retailer order procurement and fulfillment service quality as well as customer perceptions of price, overall satisfaction and willingness to use the same online retailers again in the future. Because the review site offers details about the survey, we were able access the survey results online. In fact, this online customer review data source has been widely used in previous studies [2], [46-48].

Each customer answered two separate surveys. The first survey is made available through an automated message on the website after the customer places an online order. The survey addresses the retailer's order procurement service quality by asking about the retailer's website design, information clarity, and search efficiency. The second survey is e-mailed after the customer receives the order. This survey includes questions about the retailer's order fulfillment service quality by asking about on-time delivery, item availability, and order tracking service. After knowing the details about the surveys, one of the authors confirmed the rigor of the survey process and validity of the survey questions by making an online purchase from one of the affiliated retailers. Additional data refinement was not necessary because the surveys used a 10-Likert scale.

From the review website, we sampled a total of 619 retailers whose service quality information was available online and had more than 50 customer reviews from customers who participated in the surveys. After collecting all necessary information, we used SPSS to further process the data, assess reliability and validity, and test the hypotheses. Because order procurement and fulfillment quality were measured by multi-items in the surveys, dimension reduction was required. For this purpose, exploratory factor analysis was used. As summarized in Table 3, the analysis clearly showed two hidden factors and they were named "order procurement quality" and "order fulfillment quality." We confirmed the two factors by assessing the face validity of individual items. Cronbach's alphas for both factors were all higher than 0.9 which indicate good reliability of items within the individual factors.

The factor analysis employed an orthogonal rotation method. By using this method, correlations between different factor scores will be zero which minimizes the issue of multicollinearity (see Table 5). One popular orthogonal factor rotation method is Varimax. Varimax maximizes the sum of the variances of the squared loadings of a factor. Another method (Equamax) attempts to minimize the number of factors as well as maximize the sum of the variances. Our data set led to exactly the same rotation results between Varimax and Equamax. The resulting factor scores were used for hypothesis testing in the logistic regression analysis. 
Table 3. Results of the principal component factor analysis and Cronbach's $\alpha$

\begin{tabular}{|c|c|c|c|c|c|}
\hline \multirow{2}{*}{$\begin{array}{c}\text { Construct } \\
\text { (Latent factor } \\
\text { named) }\end{array}$} & \multirow{2}{*}{ Indicators } & \multicolumn{2}{|c|}{ Component $^{1}$} & \multirow{2}{*}{$\%$ variance } & \multirow{2}{*}{$\begin{array}{l}\text { Cronbach' } \\
\text { alpha }\end{array}$} \\
\hline & & 1 & 2 & & \\
\hline \multirow{3}{*}{$\begin{array}{l}\text { Order fulfilment } \\
\text { quality }\end{array}$} & "On-time delivery" & .933 & .203 & \multirow{3}{*}{62.3} & \multirow{3}{*}{0.915} \\
\hline & "Order tracking" & .926 & .176 & & \\
\hline & "Availability of product you wanted" & .845 & .240 & & \\
\hline \multirow{3}{*}{$\begin{array}{c}\text { Order procurement } \\
\text { quality }\end{array}$} & "Easy finding what you are looking for" & .174 & .930 & \multirow{3}{*}{24.2} & \multirow{3}{*}{0.922} \\
\hline & "Design of website" & .147 & .916 & & \\
\hline & "Clarity of information" & .338 & .866 & & \\
\hline
\end{tabular}

${ }^{1}$ Two orthorgonal factor rotation methods, Varimax and Equamax, resulted in identical factor scores.

Table 4. Descriptive statistics of 619 retailers in the sample

\begin{tabular}{ll}
\hline Reputation & $\begin{array}{l}\text { Reputable retailers: } 134 \\
\text { Non-reputable retailers: } 485\end{array}$ \\
\hline Social media & $\begin{array}{l}\text { Social media non-users: } 87 \\
\text { Social media users: } 532\end{array}$ \\
& $-\quad$ Facebook users: 530 \\
& $-\quad$ Twitter users: 480 \\
& $-\quad$ YouTube users: 239 \\
- & One social medium users: 45 \\
& $-\quad$ Two social media users: 257 \\
- & Three social media users: 230 \\
\hline
\end{tabular}


Table 5. Pearson correlation matrix

\begin{tabular}{|c|c|c|c|c|c|c|}
\hline & Facebook use & Twitter use & YouTube use & \#Social media & OFQ & OPQ \\
\hline \multicolumn{7}{|l|}{ Facebook use } \\
\hline Twitter use & $.739 * *$ & & & & & \\
\hline YouTube use & $.326^{* *}$ & $.356 * *$ & & & & \\
\hline \#Social media & $.815^{* *}$ & $.847 * *$ & $.747 * *$ & & & \\
\hline OFQ & .015 & .001 & .035 & .023 & & \\
\hline OPQ & .056 & .006 & .054 & .048 & .000 & \\
\hline Reputation & .070 & $.086 *$ & $.163 * *$ & $.139 * *$ & .046 & .051 \\
\hline
\end{tabular}

Table 6. Results of binary logistic regression analyses

\begin{tabular}{|c|c|c|c|c|c|c|c|c|}
\hline \multirow{2}{*}{$\begin{array}{c}\text { Odds } \\
\text { Variables }\end{array}$} & \multicolumn{2}{|c|}{$\begin{array}{c}\text { Reputation (yes/no) } \\
\left(\text { Facebook }^{\mathrm{a}}\right)\end{array}$} & \multicolumn{2}{|c|}{$\begin{array}{l}\text { Reputation (yes/no) } \\
\left.\text { (Twitter }{ }^{\mathrm{a}}\right)\end{array}$} & \multicolumn{2}{|c|}{$\begin{array}{c}\text { Reputation (yes/no) } \\
\text { (YouTube }^{\text {a }} \text { ) }\end{array}$} & \multicolumn{2}{|c|}{$\begin{array}{c}\text { Reputation (yes/no) } \\
\left(\# \text { Social media }{ }^{a}\right)\end{array}$} \\
\hline & $\mathrm{B}$ & s.e. ${ }^{b}$ & $\mathrm{~B}$ & coeff. & $\mathrm{B}$ & s.e. ${ }^{b}$ & $\mathrm{~B}$ & s.e. ${ }^{b}$ \\
\hline Constant & $-1.755^{* *}$ & 0.301 & $-1.734 * *$ & 0.237 & $-1.634 * *$ & 0.139 & $-0.837 * *$ & 0.144 \\
\hline $\mathrm{OPQ}$ & 0.177 & 0.100 & 0.128 & 0.100 & 0.113 & 0.101 & 0.110 & 0.101 \\
\hline OFQ & 0.115 & 0.103 & 0.115 & 0.104 & 0.101 & 0.103 & 0.102 & 0.103 \\
\hline Social media use ${ }^{a}$ & $0.529^{\dagger}$ & 0.318 & $0.553 *$ & 0.261 & $0.780 * *$ & 0.199 & & \\
\hline One social medium & & & & & & & $0.989 * *$ & 0.343 \\
\hline Two social media & & & & & & & $0.716^{\dagger}$ & 0.416 \\
\hline Three social media & & & & & & & $0.735 * *$ & 0.220 \\
\hline$\Delta-2 \ln ($ likelihood $)$ & \multicolumn{2}{|c|}{640.252} & \multicolumn{2}{|c|}{$637.887^{*}$} & \multicolumn{2}{|c|}{$627.285^{* *}$} & \multicolumn{2}{|c|}{$626.593 * *$} \\
\hline
\end{tabular}

\#Social media is the number of social media used; OFQ is order fulfillment quality, OPQ is order procurement quality.

${ }^{a}$ corresponding social media use in the predictor variables; ${ }^{b}$ standard error; ${ }^{\dagger} \mathrm{p}<0.10,{ }^{*} \mathrm{p}<0.05 ; * * \mathrm{p}<0.01$ 
To test Hypothesis 2, we obtained information about social media use by visiting the websites of all 619 retailers and examined each retailer's use of social media. The websites presented unique social media logos if they used certain social media such as Facebook, Twitter, and YouTube. This study looked at those three social media given their popularity and distinctive social mechanisms. Data of social media use was coded as a dichotomous variable representing the use or not use of Facebook, Twitter, and YouTube.

We examined the reputation of individual retailers through their online presence using a method by Cho [2]. This method is different from the perceptual reputation measurement utilized in previous studies. This online presence method differentiates reputable retailers from others based on information found on Wikipedia. Wikipedia contains detailed information about reputable retailers regarding locations of headquarters, annual sales, business areas, etc. Reputation and social media use of 619 Internet retailers in the sample are summarized in Table 4. Because reputation was measured as a dichotomous variable, we used binary logistic regression analysis to test the hypotheses [49-50].

\section{RESULTS}

Before running binary regression analyses, pairwise correlations among all variables were examined and presented in Table 5. This step is important for predicting the potential multicollinearity issue which came from high correlations between independent variables in a regression model. As shown in Table 5, the number and types of social media used were highly correlated. These high correlations were expected because many retailers in the sample used more than one of the three social media investigated. To minimize multicollinearity, each binary regression model was designed by adding only one of these variables to each model. The number of social media (\#Social media in Table 5 and Table 6) refers to how many of the three social media were used. In the model, retailers that did not use any of the three social media were used as a reference group

The results of the logistic regression analysis are summarized in Table 6. As shown, order procurement quality and order fulfillment quality are not significant predictors of reputation which does not support Hypothesis 1 . However, use of social media was a significant predictor of reputation depending on the social media used. YouTube and Twitter use were significant at .01 and .05 significance levels respectively. Facebook use was marginally significant at .10 significance level. Regression coefficients were all positive which indicate that an Internet retailer using 
social media is likely to be reputable. The last column in Table 6 shows the results by adding the number of social media used as an independent variable. This required three dummy variables for one, two, and three social media used, and retailers with no use of social media constituted the reference group. Results show that the use of one type of social media and all three media were significant at .01 level while the use of two social media was marginally significant at .10. The significance levels for three different groups show unique relationship strengths but the results confirm that use of one or more social media is significantly associated with reputation. The findings support Hypothesis 2. Overall, the results indicate that reputable retailers' service performance was not different from non-reputable retailers, but the former used social media more than non-reputable retailers. Among the three social media, YouTube showed a highly significant relationship with reputation.

\section{DISCUSSION AND IMPLICATIONS}

The findings in this study provide important information that advances our knowledge on reputation development and reputable Internet retailers' business practices. In contrast to previous findings that service quality is essential for reputation creation, our data did not support the connection between service quality and reputation. We found that reputable Internet retailers do not necessarily provide higher service quality than non-reputable retailers.

There are two potential explanations for the conflicting findings. First, it is possible that retailers change their service performance after they become reputable. Online customers trust reputable retailers almost unconditionally [23-24]. Thus, retailers with good reputations might not feel the need to focus on service quality after they obtain a good reputation. Providing exceptional service to customers is expensive for internet retailers because they have to thoroughly study customer preferences, more frequently change their web design, and monitor their supply chains accordingly [27], [3]. Reducing these maintenance costs increases their profit and their current reputation should protect profits by securing sales under less exceptional service performance. A second explanation for the conflicting findings might be that some retailers could have been reputable outside of their online business in the past regardless of their e-business today. For instance, well-known retailers with a wide network (e.g., Walmart, Staples, and Best Buy) have built their reputation from brick-and-mortar stores and are capitalizing on their reputation in the new e-business. Because they already have a reputation from offline 
business operations, they might not be highly motivated to further develop their reputation through their Internet retailing operations.

In contrast to service quality, social media use has a significant relationship with reputation. In particular, the significant associations between Internet retailer reputation and use of Twitter and YouTube suggest that reputable retailers are more active in social media marketing than non-reputable retailers. It is interesting that the significance levels for Facebook $(\mathrm{p}=0.1)$, Twitter $(\mathrm{p}=0.05)$, and YouTube $(\mathrm{p}=0.01)$ parallels the order of popularity of social media use by the retailers. Among the 619 retailers in our sample, $530(85.6 \%)$ used Facebook, $480(77.5 \%)$ used Twitter, and only 239 (38.6\%) used YouTube. The relative popularity of the social media might explain the significance levels among social media regarding their association with reputation. The high popularity of Facebook implies that many non-reputable retailers may use Facebook which would blur the differences between reputable and non-reputable retailers' use of this social medium.

Conversely, a relatively lower use of YouTube among Internet retailers suggests that only retailers with adequate resources can use this social medium. This finding points to the cost of social media use as a key differentiator between reputable and non-reputable retailers. It may be expensive to implement social media marketing and this cost factor can favor reputable retailers who can afford it. Moreover, the cost of using social media may vary by individual social media. One reason why Facebook and Twitter are popular among Internet retailers might be their low cost of social networking [39], [51]. The cost for YouTube marketing might be higher because it requires extra efforts to transform their marketing intent to a streaming/video format. This explains that fewer retailers use YouTube compared to Facebook and Twitter. Reputable retailers may be better able to afford the cost of using YouTube as a marketing tool.

The findings regarding service quality and social media reveal some important practices of reputable internet retailers and some challenges that confront non-reputable retailers. Reputable retailers more actively use social media and their reputation helps not only manage customer relationships but also resource allocation. Reputation contributes to customer relationships because of the positive image already held by customers. In addition, reputation allows Internet retailers to move their resources from service maintenance to social media marketing. Because of their reputation, they can limit the resources needed to provide higher service quality because customers perceived reputable retailers' service 
quality to be high [14-16]. This flexibility in resource allocation may not be available to non-reputable retailers. Therefore, a challenge for non-reputable retailers may be to decide whether to allocate scarce resources to both service quality and social media marketing. This challenge of resource allocation seems to limit their access to multiple social media.

Regarding the challenges that non-reputable retailers confront, the future does not look solely negative. As the popularity of social media has increased, information transparency between retailers and customers has been dramatically enhanced. Even non-reputable retailers can encourage customers to post comments to their personal social media forums. Such voluntary customer postings and the availability of lower cost social media make this reputation-building technique more accessible to non-reputable retailers.

In addition, the use of social media marketing also has risks. For example, information transparency could result in negative word-of-mouth feedback that can easily damage retailer reputation [7-8]. Non-reputable retailers may choose to avoid the risks and costs associated with social media marketing and focus on their service quality.

\section{LIMITATIONS AND FUTURE RESEARCH}

This study explores the connection between service quality and reputation of Internet retailers based on the assumptions that service quality and social media marketing represent two major reputation predictors in the industry sector. These assumptions were based on an extensive review of the literature. Nevertheless, additional minor factors may be relevant to reputation. From a study design perspective, including only two predictors of reputation is a limitation of this study especially since our analysis unexpectedly revealed that service quality was not related to reputation. This limitation invites future research to investigate other predictors of reputation. As discussed in the previous section, one plausible predictor our findings suggest is the cost of using social media. Future research could explore the relationship between the affordability of social media and reputation.

In addition, most research on the reputation creation process has focused on customer perception but there is little research on an objective reputation measurement. Our finding of the poor connection between service quality and reputation indicates the need for future research into an objective reputation measurement beyond customer perception. This 
would complement previous studies on reputation within customer perceptions.

\section{REFERENCES}

[1] E. Savelli, M. Cioppi, and F. Tombari, Web atmospherics as drivers of shopping centres' customer loyalty. International Journal of Retail \& Distribution Management, 45(11), 1213-1240, 2017.

[2] Y. K. Cho, Creating customer repurchase intention in Internet retailing: The effects of multiple service events and product type. Journal of Retailing and Consumer Services, 22(1), 213-222, 2015.

[3] D. M. Szymanski and R. T. Hise, E-satisfaction: An initial examination", Journal of Retailing, 76(3), 309-322, 2000.

[4] A. Parasuraman, V. A. Zeithaml, and A. Malhotra, E-S-QUAL: A multiple-item scale for assessing electronic service quality. Journal of Service Research, 7(3), 213-233, 2005.

[5] A. Parasuraman, V. A. Zeithaml, and L. L. Berry, A conceptual model of service quality and its implications for future research. Journal of Marketing, 49(Fall), 41-50, 1985.

[6] I. Sinha, Cost transparency: The net's real threat to prices and brands. Harvard Business Review, 78(2), 43-50, 2000).

[7] J. Pfeffer, T. Zorbach, and K. M. Carley, Understanding online firestorms: Negative word-of-mouth dynamics in social media networks. Journal of Marketing Communications, 20(1-2), 117-128, 2014.

[8] J. Du, X. Fan, and T. Feng, Group emotional contagion and complaint intentions in group service failure: The role of group size and group familiarity. Journal of Service Research, 17(3), 326-338, 2014.

[9] W. H. Weiger, H. A. Wetzel, and M. Hammerschmidt, Leveraging marketer-generated appeals in online brand communities: An individual user-level analysis. Journal of Service Management, 28(1), 133-156, 2017.

[10] A. Jakic, M. O. Wagner, and A. Meyer, The impact of language style accommodation during social media interactions on brand trust. Journal of Service Management, 28(3), 418-441, 2017.

[11] K. Yang, X. Li, H. Kim, and Y. H. Kim, Social shopping website quality attributions increasing consumer participation, positive eWOM, and coshopping: The reciprocating role of participation. Journal of Retailing and Consumer Services, 24(1), 1-9, 2015.

[12] N. Y. Jung, S. Kim, and S. Kim, Influence of consumer attitude toward online brand community on revisit intention and brand trust. Journal of Retailing and Consumer Services, 21(4), 581-589, 2014. 
[13] A. J. Kim and E. Ko, Do social media marketing activities enhance customer equity? An empirical study of luxury fashion brand. Journal of Business Research, 65(10), 1480-1486, 2012.

[14] P. Punyatoya, Effects of cognitive and affective trust on online customer behavior. Marketing Intelligence \& Planning, 37(1), 80-96, 2019.

[15] N. S. Terblanche, Customer experiences, interactions, relationships and corporate reputation: a conceptual approach. Journal of General Management, 35, 5-17, 2009.

[16] W. Ruimei, W. Shengxiong, W. Tianzhen, and Z. Xiling, Customers e-trust for online retailers: A case in China. Paper presented at the Eighth International Conference on Computational Intelligence and Security, November 573-577, 2012.

[17] B. Jin, J. Y. Park, and J. Kim, Cross-cultural examination of the relationships among firm reputation, e-satisfaction, e-trust, and eloyalty", International Marketing Review, 25(3), 324-337, 2008.

[18] S. Wang, S. E. Beatty, and W. Foxx, Signaling the trustworthiness of small online retailers. Journal of Interactive Marketing, 18(1), 53-69, 2004.

[19] R. Järvinen and K. Suomi, Reputation attributes in retailing services: managerial perspective. Managing Service Quality: An International Journal, 21(4), 410-423, 2011.

[20] A. Caruana and M. T. Ewing, How corporate reputation, quality, and value influence online loyalty. Journal of Business Research, 63(9-10), 1103-1110, 2010.

[21] P. A. Argenti and B. Druckenmiller, Reputation and the corporate brand. Corporate Reputation Review, 6(4), 368-374, 2004.

[22] J. Kim and S. J. Lennon, Effects of reputation and website quality on online consumers' emotion, perceived risk and purchase intention: Based on the stimulus-organism-response model. Journal of Research in Interactive Marketing, 7(1), 33-56, 2013.

[23] G. Walsh, A. K. Albrecht, W. Kunz, and C. F. Hofacker, Relationship between online retailers' reputation and product returns. British Journal of Management, 27(1), 3-20, 2016.

[24] I. P. Riquelme, S. Román, P. J. Cuestas, and D. Iacobucci, The dark side of good reputation and loyalty in online retailing: When trust leads to retaliation through price unfairness. Journal of Interactive Marketing, 47, 35-52, 2019.

[25] L. C. Har, and U. C. Eze, Factors influence consumers' intentions to repurchase online in Malyasia. International Journal of Electronic Commerce Studies, 2(2), 157-164, 2011. 
[26] A. Parasuraman, V. A. Zeithaml, and L. L. Berry, A conceptual model of service quality and its implications for future research. Journal of Marketing, 49(4), 41-50, 1985.

[27] J. Rowley, An analysis of the e-service literature: Toward a research agenda. Internet Research, 16(3), 339-359, 2006.

[28] Y. Cho, I. Im, and R. Hiltz, The impact of e-services failures and customer complaints on electronic commerce customer relationship management. Journal of Consumer Satisfaction, Dissatisfaction and Complaining Behavior, 23(2), 106-118, 2003.

[29] J. E. Kendall, E-distance and the theatres of South Jersey. Decision Line, 32(2), 13-15, 2003.

[30] Y. K. Cho, Service quality and price perceptions by Internet retail customers: Linking the three stages of service interaction. Journal of Service Research, 17(4), 432-445, 2014.

[31] A. Kumar and B. Anjaly, How to measure post-purchase customer experience in online retailing? A scale development study. International Journal of Retail \& Distribution Management, 45(12), 1277-1297, 2017.

[32] S. Rao, S. E. Griffis, and T. J. Goldsby, Failure to deliver? Linking online order fulfillment glitches with future purchase behavior. Journal of Operations Management, 29(7), 692-703, 2011.

[33] Y. Cao and H. Zhao, Evaluation of e-tailers' delivery fulfillment: Implications of firm characteristics and buyer heterogeneity, Journal of Service Research, 6(4), 347-360, 2004.

[34] C. Dijkmans, P. Kerkhof, and C. J. Beukeboom, A stage to engage: Social media use and corporate reputation. Tourism management, 47 , 58-67, 2015.

[35] B. J. Baldus, Leveraging online communities to support the brand and develop the community. Journal of Internet Commerce, 17(2), 115-144, 2018.

[36] M. Laroche, M. R. Habibi, and M. O. Richard, To be or not to be in social media: How brand loyalty is affected by social media? International Journal of Information Management, 33(1), 76-82, 2013.

[37] G. Helal, W. Ozuem, and G. Lancaster, Social media brand perceptions of millennials. International Journal of Retail \& Distribution Management, 46(10), 977-998, 2018.

[38] M. Mathur, Leveraging social media-based determinants to build customer-based brand equity of a retailer. The International Review of Retail, Distribution and Consumer Research, 28(5), 554-575, 2018. 
[39] S. L. Wartick, The relationship between intense media exposure and change in corporate reputation. Business \& Society, 31(1), 33-49, 1992.

[40] H. Zhang, Y. Lu, X. Shi, Z. Tang, and Z. Zhao, Mood and social presence on consumer purchase behavior in C2C E-commerce in Chinese culture. Electronic Markets, 22(3), 143-154, 2012.

[41] K. N. Shen and M. Khalifa, System design effects on online impulse buying. Internet Research, 22(4), 396-425, 2012.

[42] A. M. Kaplan and M. Haenlein, Users of the world, unite! The challenges and opportunities of social media. Business Horizon, 53(1), 59-68, 2010.

[43] R. L. Daft and R. H. Lengel, Organizational information requirements, media richness and structural design. Management Science, 32(5), 554-571, 1986.

[44] C. J. W. Ledford, Changing channels: A theory-based guide to selecting traditional, new, and social media in strategic social marketing. Social Marketing Quarterly, 18(3), 175-186, 2012.

[45] M. Etter, D. Ravasi, and E. Colleoni, Social media and the formation of organizational reputation. Academy of Management Review, 44(1), 28-52, 2019.

[46] G. R. Heim and K. K. Sinha, Operational drivers of customer loyalty in electronic retailing: An empirical analysis of electronic food retailers. Manufacturing \& Service Operations Management, 3(3), 264-271, 2001.

[47] S. Thirumalai and K. K. Sinha, Customer satisfaction with order fulfillment in retail supply chains: implications of product type in electronic B2C transactions. Journal of Operations Management, 23(3-4), 291-303, 2005.

[48] S. Otim and V. Grover, An empirical study on web-based services and customer loyalty. European Journal of Information Systems, 15(6), 527-541, 2006.

[49] B. Abraham and J. Ledolter, Introduction to Regression Modeling. Thomson Brooks/Cole Belmont, CA, 2006.

[50] J. F. Hair, W. C. Black, B. J. Babin, R.E. Anderson, and R. I. Tatham, Multivariate data analysis. ( ${ }^{\text {th }}$ ed.). Upper Saddle River, NJ: Pearson Prentice Hall, 2005.

[51] A. K. Kirtiş and F. Karahan, To be or not to be in social media arena as the most cost-efficient marketing strategy after the global recession. Procedia-Social and Behavioral Sciences, 24, 260-268, 2011. 
